\title{
High serum carotenoids associated with lower risk for the metabolic syndrome and its components among Japanese subjects: Mikkabi cohort study
}

\author{
Minoru Sugiura $^{1 *}$, Mieko Nakamura ${ }^{2}$, Kazunori Ogawa ${ }^{1}$, Yoshinori Ikoma ${ }^{1}$ and Masamichi Yano ${ }^{1}$ \\ ${ }^{1}$ Citrus Research Division, NARO Institute of Fruit Tree Science, National Agriculture and Food Research Organization, \\ 485-6 Okitsu-nakachou, Shimizu, Shizuoka City, Shizuoka 424-0292, Japan \\ ${ }^{2}$ Department of Community Health and Preventive Medicine, Hamamatsu University School of Medicine, 1-20-1 Handayama, \\ Hamamatsu, Shizuoka 431-3192, Japan
}

(Submitted 13 April 2015 - Final revision received 21 July 2015 - Accepted 29 July 2015 - First published online 14 September 2015)

\section{Abstract}

Recent epidemiological studies show the association of carotenoids with the metabolic syndrome (MetS), but thorough longitudinal cohort studies regarding this association have not been well conducted. The objective of this study was to investigate longitudinally whether serum carotenoids are associated with the risk of developing the MetS and its components in Japanese subjects. We conducted a follow-up study on 1073 men and women aged 30-79 years at the baseline from the Mikkabi prospective cohort study. Those who participated in the baseline and completed follow-up surveys were examined longitudinally. Over the 10-year period, 910 subjects (295 men and 615 women) took part in the follow-up survey at least once. Over a mean follow-up period of $7 \cdot 8$ (sD 2.9) years, thirty-six men and thirty-one women developed new MetS. After adjustments for confounders, the hazard ratio (HR) for the MetS in the highest tertile of serum $\beta$-carotene against the lowest tertile was 0.47 (95\% CI $0.23,0.95)$. On the other hand, significantly lower risks for dyslipidaemia were observed in the highest tertiles of serum $\alpha$ - and $\beta$-carotene and $\beta$-cryptoxanthin (HR 0.66; $95 \%$ CI 0.46, 0.96; HR, 0.54; 95\% CI 0.37, 0.79; and HR 0.66; $95 \%$ CI 0.44, 0.99, respectively). Other significant associations between the risks for obesity, high blood pressure and hyperglycaemia with serum carotenoids were not observed. Our results further support the hypothesis that eating a diet rich in carotenoids might help prevent the development of the MetS and its complications in Japanese subjects.

\section{Key words: Antioxidants: Carotenoids: Metabolic syndrome: Longitudinal studies: Cohort studies}

The metabolic syndrome (MetS) is a cluster of metabolic risk factors; it includes excess weight, hyperglycaemia, elevated blood pressure, low HDL-cholesterol and hypertriacylglycerolaemia ${ }^{(1,2)}$. The MetS increases the risk for diabetes and CVD, and this syndrome is emerging as one of the major medical and public health problems, not only in Japan but worldwide ${ }^{(3)}$. Given the impending worldwide epidemic of obesity, diabetes and CVD, strategies aimed at increasing our understanding of the pathology of the syndrome, as well as those aimed at preventing or treating people with the syndrome, are urgently required.

Numerous recent epidemiological studies have demonstrated that eating a diet rich in fruits and vegetables is inversely associated with the risk of the MetS ${ }^{(4-11)}$. Antioxidant vitamins and carotenoids exist in abundance in fruit and vegetables, and they have been shown to assist the body's defence against oxidative stress induced by reactive oxygen species and free radicals $^{(12,13)}$. On the other hand, in some recent studies, it has been reported that oxidative stress, which is an imbalance between pro-oxidants and antioxidants, occurs more frequently in subjects with the MetS than in those without the MetS ${ }^{(14,15)}$. Therefore, antioxidant vitamins and carotenoids might be beneficial in preventing the MetS.

Recently, seven cross-sectional studies have shown the association of serum antioxidant status with the $\operatorname{MetS}^{(16-22)}$. However, thorough longitudinal cohort studies regarding this association have not been well conducted. To our knowledge, only one prospective study has been reported ${ }^{(23)}$. Czernichow et al. ${ }^{(23)}$ reported that antioxidant supplementation for 7.5 years did not affect the risk for developing the MetS, but in observational prospective examination baseline serum $\beta$-carotene was negatively associated with the risk for the MetS in the French randomised placebo-controlled SU.VI.MAX (Supplementation en VItamines et Mine'raux AntioXydants) trial. These results indicate that eating a diet rich in carotenoids, especially $\beta$-carotene, may have a protective effect against the development of the MetS. Previously, we found that serum carotenoids, especially $\beta$-carotene, were negatively associated with the risk for the MetS in middle-aged and older Japanese subjects ${ }^{(17)}$.

Abbreviations: HR; hazard ratio; MetS; metabolic syndrome.

* Corresponding author: M. Sugiura, fax +81 54369 2115, email msugiura@affrc.go.jp 
However, these data consisted of cross-sectional analyses. Therefore, only limited inferences can be made regarding temporality and causation. To determine whether carotenoids may help prevent the MetS in Japanese subjects, further cohort studies will be required.

The objective of this study was to investigate longitudinally whether the risk of developing the MetS and its components is associated with serum carotenoid concentrations in middleaged and older Japanese subjects. The associations of six serum carotenoid concentrations, that is, lutein, lycopene, $\alpha$-carotene, $\beta$-carotene, $\beta$-cryptoxanthin and zeaxanthin, with the MetS and its components were evaluated longitudinally.

\section{Methods}

\section{Ethics statement}

This study was carried out in accordance with the Declaration of Helsinki and approved by the ethics committee of the NARO Institute of Fruit Tree Science and the Hamamatsu University School of Medicine. We obtained written informed consent from all participants involved in our study.

\section{Study population}

This was a prospective survey involving participants in the Mikkabi cohort study conducted in the town of Mikkabi, Shizuoka Prefecture, Japan. The Mikkabi cohort study was conducted on two cohorts: one initiated in 2003 (cohort I) and the other in 2005 (cohort II). The study design has been described previously ${ }^{(17)}$.

After a baseline survey (2003 and 2005), subjects were invited to participate in a follow-up survey in 2005 (for cohort I), 2006, 2007, 2008, 2009 and 2013. Subjects in cohort I were followed up from 2005, and subjects in cohort II were followed up from 2006, through September 2013. In this manner, 2-year follow-up data were obtained from forty participants. In the same way, 3-, 4-, 5-, 6-, 8- and 10-year follow-up data were obtained from forty-one, ninety-five, forty-seven, 161, ninety-four and 432 participants, respectively. In total, from the six follow-up surveys, 910 subjects ( 295 men and 615 women) took part in the follow-up survey at least one time. The follow-up rate was $84.9 \%$. The person-years of follow-up were calculated for each subject from the starting point to the date of diagnosis.

The concentrations of six serum carotenoids at the baseline survey, lutein, lycopene, $\alpha$-carotene, $\beta$-carotene, $\beta$-cryptoxanthin and zeaxanthin, were analysed by reverse-phase HPLC using $\beta$-apo-8'-carotenal as an internal standard at the Laboratory of Public Health and Environmental Chemistry, Kyoto Biseibutsu Kenkyusho, as described previously ${ }^{(24)}$. All blood measurements, except for the serum carotenoid concentrations, were conducted at the laboratory of the Seirei Preventive Health Care Center. Subjects' heights and body weight were measured by trained public health nurses. The BMI was calculated as the body weight ( $\mathrm{kg}$ ) divided by the height squared $\left(\mathrm{m}^{2}\right)$. Blood pressure was measured using an automated sphygmomanometer, model BP-103iII (Nihon Colin Inc.).

A self-administered questionnaire was used to collect information about subjects' histories of chronic diseases, medication uses and lifestyles, as described previously ${ }^{(17)}$. The MetS was defined as obesity (BMI $\geq 25 \mathrm{~kg} / \mathrm{m}^{2}$ ) and as having two or more MetS components such as hypertension, hyperglycaemia and/or dyslipidaemia, as described previously ${ }^{(17)}$. Individuals who were currently using medications for diabetes, hypertension or dyslipidaemia were defined as exhibiting each of the MetS components. The occurrence of the MetS and its components was identified by the results from follow-up health examinations and self-administered questionnaires. In our study, the MetS was diagnosed according to Japanese criterion ${ }^{(25,26)}$. However, we have no data concerning waist circumference in our survey. Therefore, we used BMI as a measure of obesity instead of waist circumference. A value $\geq 25 \mathrm{~kg} / \mathrm{m}^{2}$ of BMI was defined as the elevated BMI proposed by the Japan Society for the Study of Obesity ${ }^{(27)}$.

\section{Statistical analysis}

The serum carotenoid concentrations, fasting plasma glucose (FPG) and serum TAG were skewed towards higher concentrations. These values were $\log _{e}$ (natural)-transformed to improve the normality of their distribution. An unpaired $t$ test was used to compare the means of continuous variables in the two groups. A $\chi^{2}$ test was used to compare percentages in the two groups. All variables were presented as an original scale. The data are expressed as the mean values and standard deviations; geometric means and $95 \%$ CI or percentages.

To assess the relationship between the serum carotenoid concentrations at baseline and the development of the MetS, Cox proportional-hazards regression analyses were performed after excluding subjects with a diagnosis of the MetS at baseline. Participants were divided into three categories according to tertiles of serum baseline carotenoid concentrations after being stratified by sex, because serum carotenoid concentrations differ substantially between male and female subjects. Hazard ratios (HR) and $95 \% \mathrm{CI}$ were calculated for the categories of serum carotenoid concentrations at the baseline in tertiles for men and women combined, with the lowest tertiles as the reference, by using the Cox proportional-hazards model and adjusting for potential confounding variables. In a similar way, we analysed the relationship between the serum carotenoid concentrations at baseline and the development of a high BMI (BMI $\left.\geq 25 \mathrm{~kg} / \mathrm{m}^{2}\right)$, high blood pressure $(\geq 130 / 85 \mathrm{mmHg}$ ), low HDL-cholesterol $(<1.04 \mathrm{mmol} / \mathrm{l})$ or high serum TAG $(\geq 1.70 \mathrm{mmol} / \mathrm{l})$, and/or high plasma glucose $(\geq 6.11 \mathrm{mmol} / \mathrm{l})$ after excluding subjects with a diagnosis of high BMI $\left(\mathrm{BMI} \geq 25 \mathrm{~kg} / \mathrm{m}^{2}\right)$, hypertension $(\geq 130 / 85 \mathrm{mmHg})$, dyslipidaemia (low HDL-cholesterol $(<1.04 \mathrm{mmol} / \mathrm{l})$ or high serum TAG $(\geq 1.70 \mathrm{mmol} / \mathrm{l})$ ) and/or hyperglycaemia (FPG $\geq 6.11 \mathrm{mmol} / \mathrm{l})$ at baseline, respectively. We also assessed linear associations by using the mean values of serum carotenoid concentrations at the baseline for each tertile. We did not adjust each carotenoid concentration in the multivariate models because Pearson's correlation analyses of serum carotenoid concentrations revealed significant positive correlations among all combinations of the six carotenoids. Pearson's correlation coefficients ranged from 0.252 for lutein and lycopene $(P<0.001)$ to 0.789 for lutein and zeaxanthin $(P<0 \cdot 001)$. All statistical analyses 
were performed using a statistical software package for Windows (SPSS version 12.0J, SPSS Inc.) on personal computers.

\section{Results}

\section{Baseline characteristics and metabolic syndrome status in} study subjects

Table 1 shows the characteristics of study subjects at the baseline survey stratified by sex. The prevalence rates of the
MetS at baseline in male and female subjects were 11.9 and $3.9 \%$, respectively. In a similar way, the prevalence rates of high BMI, high blood pressure, high plasma glucose and low HDL-cholesterol or high serum TAG in male subjects were significantly higher than those in female subjects. On the other hand, serum carotenoid concentrations, except for zeaxanthin, were significantly higher in female subjects than in male subjects. In our follow-up survey, the prevalence rate of the MetS at the baseline survey was not different between the fallout and follow-up subjects (data not shown).

Table 1. Characteristics of the study subjects at baseline survey*

(Mean values and standard deviations; geometric means and $95 \%$ confidence intervals; percentages)

\begin{tabular}{|c|c|c|c|c|}
\hline & \multicolumn{2}{|c|}{ Male } & \multicolumn{2}{|c|}{ Female } \\
\hline & Mean & SD & Mean & SD \\
\hline$n$ & \multicolumn{2}{|c|}{295} & \multicolumn{2}{|c|}{615} \\
\hline Age (years) & $56 \cdot 2$ & $9 \cdot 7$ & $54 \cdot 4^{\star *}$ & 9.9 \\
\hline $\mathrm{BMI}\left(\mathrm{kg} / \mathrm{m}^{2}\right)$ & 23.6 & $2 \cdot 9$ & $22 \cdot 5^{\star *}$ & 3.1 \\
\hline Systolic blood pressure $(\mathrm{mmHg})$ & $132 \cdot 1$ & $19 \cdot 3$ & $129 \cdot 2^{*}$ & $19 \cdot 4$ \\
\hline Diastolic blood pressure (mmHg) & 80.7 & $12 \cdot 0$ & $75 \cdot 6^{\star *}$ & 11.2 \\
\hline \multicolumn{5}{|l|}{ Fasting plasma glucose $(\mathrm{mmol} / \mathrm{l})$} \\
\hline Mean & \multirow{2}{*}{\multicolumn{2}{|c|}{$\begin{array}{c}5 \cdot 51 \\
5 \cdot 40,5 \cdot 63\end{array}$}} & \multirow{2}{*}{\multicolumn{2}{|c|}{$\begin{array}{c}5 \cdot 16^{\star *} \\
5 \cdot 11,5 \cdot 21\end{array}$}} \\
\hline $95 \% \mathrm{Cl}$ & & & & \\
\hline HDL-cholesterol (mmol/l) & 1.51 & 0.44 & $1.78^{\star \star}$ & 0.41 \\
\hline \multicolumn{5}{|l|}{ Serum TAG (mmol/l) } \\
\hline Mean & \multirow{2}{*}{\multicolumn{2}{|c|}{$\begin{array}{c}1 \cdot 28 \\
1 \cdot 20,1 \cdot 37\end{array}$}} & \multicolumn{2}{|c|}{$0.93^{\star \star}$} \\
\hline $95 \% \mathrm{Cl}$ & & & & \\
\hline \multicolumn{5}{|l|}{ Prevalence of MetS and its components (\%) } \\
\hline MetS & \multicolumn{2}{|c|}{11.9} & \multicolumn{2}{|c|}{$3.9+\dagger$} \\
\hline Elevated BMI $\left(\geq 25 \mathrm{~kg} / \mathrm{m}^{2}\right)$ & \multicolumn{2}{|c|}{29.8} & \multicolumn{2}{|c|}{$17 \cdot 6+\dagger$} \\
\hline Elevated blood pressure $(\geq 130 / 85 \mathrm{mmHg})$ & \multicolumn{2}{|c|}{$58 \cdot 6$} & \multicolumn{2}{|c|}{$50 \cdot 2 \dagger$} \\
\hline Elevated plasma glucose $(\geq 6.11 \mathrm{mmol} / /)$ & \multirow{2}{*}{\multicolumn{2}{|c|}{$\begin{array}{l}17.6 \\
32.5\end{array}$}} & \multirow{2}{*}{\multicolumn{2}{|c|}{$8.0 \dagger \dagger$}} \\
\hline Low HDL-cholesterol $(<1.04 \mathrm{mmol} / \mathrm{l})$ or elevated serum TAG $(\geq 1.70 \mathrm{mmol} / \mathrm{l})$ & & & & \\
\hline \multicolumn{5}{|l|}{ Total energy intake } \\
\hline Including ethanol $(\mathrm{kJ} / \mathrm{d})$ & $9099 \cdot 8$ & $2256 \cdot 0$ & $8361 \cdot 7$ & $2230 \cdot 1$ \\
\hline Including ethanol (kcal/d) & 2174.9 & $539 \cdot 2$ & $1998 \cdot 5^{\star \star}$ & $533 \cdot 0^{\star \star}$ \\
\hline Excluding ethanol $(\mathrm{kJ} / \mathrm{d})$ & $8370 \cdot 9$ & 2120.5 & 8311.9 & $2233 \cdot 0$ \\
\hline Excluding ethanol (kcal/d) & $2000 \cdot 7$ & $506 \cdot 8$ & $1986 \cdot 6$ & 533.7 \\
\hline \multicolumn{5}{|l|}{ Serum carotenoid concentrations $(\mu \mathrm{mol} / /) \ddagger$} \\
\hline \multicolumn{5}{|l|}{ Lutein } \\
\hline Mean & \multirow{2}{*}{\multicolumn{2}{|c|}{$\begin{array}{c}0.53 \\
0.51,0.56\end{array}$}} & & \\
\hline $95 \% \mathrm{Cl}$ & & & & \\
\hline Lycopene & & & & \\
\hline Mean & & & & \\
\hline $95 \% \mathrm{Cl}$ & & & & \\
\hline a-Carotene & & & & \\
\hline Mean & & & & \\
\hline $95 \% \mathrm{Cl}$ & & & & \\
\hline$\beta$-Carotene & & & & \\
\hline Mean & & & & \\
\hline $95 \% \mathrm{Cl}$ & & & & \\
\hline$\beta$-Cryptoxanthin & & & & \\
\hline Mean & & & & \\
\hline $95 \% \mathrm{Cl}$ & & & & \\
\hline Zeaxanthin & & & & \\
\hline Mean & & & & \\
\hline $95 \% \mathrm{Cl}$ & & & & \\
\hline Current tobacco use (\%) & & & & \\
\hline Exercise habits $(\%) \S$ & & & & \\
\hline Regular alcohol intake (\%)§ & & & & \\
\hline
\end{tabular}

MetS, metabolic syndrome.

Significantly different from male subjects group: ${ }^{*} P<0.05,{ }^{\star *} P<0.01$ (unpaired $t$ test).

Significantly different from male subjects group: $\dagger P<0.05$, $+\uparrow P<0.01$ ( $x^{2}$ test).

$\ddagger$ These variables were represented as original scale after analysis by log (natural)-transformed values.

$\S \geq 1$ Times/week. 


\section{Risk of metabolic syndrome according to tertiles of baseline} serum carotenoid concentrations

The HR of the MetS associated with the tertiles of six serum carotenoid concentrations at the baseline survey, after adjusting for confounding factors, are shown in Table 2. After adjusting for age, sex, current tobacco use, regular alcohol intake, exercise habits and total energy intake, a significantly lower HR for the MetS was observed in the highest group (T3) of serum $\beta$-carotene. On the other hand, serum lycopene, $\alpha$-carotene, $\beta$-cryptoxanthin, lutein and zeaxanthin were not associated with the risk of developing the MetS.

\section{Risk of metabolic syndrome components according to tertiles of baseline serum carotenoid concentrations}

Next, we examined the association of the risk for developing MetS components with serum carotenoid concentrations at the baseline. The HR of elevated BMI associated with the tertiles of the concentrations of the six serum carotenoids after adjusting for confounding factors are shown in online Supplementary Table S1. Lower HR were observed in the second and highest tertiles of serum lycopene, but this inverse association was not significant. On the other hand, significantly lower risks for dyslipidaemia were observed in the highest tertiles of serum $\alpha$ - and $\beta$-carotene and $\beta$-cryptoxanthin (Table 3 ). Other significant associations between the risks for developing elevated blood pressure and high plasma glucose with the basal serum carotenoids were not observed (online Supplementary Tables S2 and S3).

\section{Discussion}

The objective of this study was to investigate longitudinally whether the risk for the MetS and its components is associated with serum carotenoid concentrations in middle-aged and older Japanese subjects. The results indicated that higher serum $\beta$-carotene at the baseline was significantly associated with a lower risk of developing the MetS. Furthermore, higher serum $\alpha$ - and $\beta$-carotene and $\beta$-cryptoxanthin levels were associated with a lower risk of developing dyslipidaemia. This is the first cohort study to examine the association of serum carotenoid concentrations with the risk of developing the MetS and its components in Japanese subjects. Numerous antioxidant vitamins and carotenoids are contained in fruits and vegetables, and several recent epidemiological studies have shown inverse associations between antioxidant vitamin and carotenoid intake or serum levels with the MetS and its components ${ }^{(16-23)}$. Our results further support the hypothesis that eating a diet rich in carotenoids, especially $\alpha$ - and $\beta$-carotene and $\beta$-cryptoxanthin, might help prevent the development of the MetS and its complications in Japanese subjects.

MetS status has an important role in the development of type-2 diabetes, stroke and $\mathrm{CVD}^{(1,2)}$. Oxidative stress, which has been involved in the pathogenesis of CVD and diabetes, may cause insulin resistance ${ }^{(28-31)}$. It is well known that oxidative stress enhances stress-sensitive signalling pathways, such as $\mathrm{NF \kappa B}$, c-Jun $\mathrm{NH}_{2}$-terminal kinase/stress-activated protein kinase, p38 mitogen-activated protein kinase and hexosamine ${ }^{(32)}$.
These signalling pathways are involved in causing insulin resistance. On the other hand, increased oxidative stress in accumulated fat may also cause obesity-associated metabolic disorders ${ }^{(33)}$. Therefore, insulin resistance and abdominal adiposity are commonly accepted to precede the other MetS risk factors via their influence on glucose and lipid metabolism and stimulation of various cytokines. Furthermore, it has been reported that oxidative stress reduces glucose uptake in muscle and $\mathrm{fat}^{(34,35)}$ and decreases insulin secretion from pancreatic $\beta$-cells ${ }^{(36)}$. Oxidative stress may also underlie the pathophysiology of hypertension ${ }^{(37)}$ and atherosclerosis ${ }^{(38)}$ by directly affecting vascular wall cells. In contrast, several studies indicate that low serum levels of carotenoids have been associated with increases in oxidative stress, diabetes, hypertension and $\mathrm{CVD}^{(39-46)}$. On the basis of this knowledge concerning the associations of oxidative stress and metabolic disorders, eating a diet rich in antioxidants might be readily accepted as a recommended strategy.

In our study, significant inverse associations between basal serum carotenoid concentrations and the risks for developing MetS components were observed only for dyslipidaemia. There were no significant associations between basal serum carotenoid concentrations and the risk of other MetS components such as elevated BMI, hypertension and hyperglycaemia. However, our findings might be partly consistent with previous reports; for example, on the basis of SU.VI.MAX data, Czernichow et $a l^{(47,48)}$ reported that antioxidant supplementation had no effect on FPG or hypertension in this study population. Furthermore, Sluijs et $a l^{(19)}$ found that dietary carotenoid intake was inversely associated with the prevalence of the MetS, waist circumferences, visceral and subcutaneous fat mass, and dyslipidaemia, but they found no associations with other MetS risk factors such as FPG or hypertension. In our previous crosssectional study, serum $\alpha$ - and $\beta$-carotene levels were significantly inversely associated with all MetS components, but a significant association between serum $\beta$-cryptoxanthin and MetS components was observed only for HDL-cholesterol ${ }^{(17)}$. On the other hand, significant inverse associations of serum lycopene, lutein and zeaxanthin levels with the risks for MetS components were also observed in our previous cross-sectional study; however, we found no associations in the present longitudinal cohort study. Although there have been very limited data about the association of serum or dietary carotenoids with the risk for developing the MetS and its components, $\alpha$ - and $\beta$-carotene and $\beta$-cryptoxanthin might help prevent the development of the MetS through improvement of dyslipidaemia among Japanese subjects. $\alpha$ - and $\beta$-carotene and $\beta$-cryptoxanthin are provitamin A carotenoids, which will be converted in the body to retinol. Retinoic acid is synthesised intracellularly from retinol, and it has a regulatory role in lipid/ glucose homoeostasis and immune function. Retinoic acid has also been implicated as an antagonist in the MetS and several inflammatory diseases ${ }^{(49)}$. In addition, although little evidence for an association between serum carotenoid levels and hyperglycaemia is present in our study, previously we found that serum carotenoid levels inversely associated with insulin resistance among non-diabetic subjects from the cross-sectional analyses $^{(50)}$. Furthermore, interestingly, Montonen et al. ${ }^{(51)}$ 
Table 2. Hazard ratios (HR) of tertiles of baseline serum carotenoid concentration on incidence of the metabolic syndrome (Mean values, HR and $95 \%$ confidence intervals)

\begin{tabular}{|c|c|c|c|c|c|c|c|c|c|c|}
\hline \multirow[b]{2}{*}{ Serum carotenoids } & \multirow[b]{2}{*}{ Mean $(\mu \mathrm{mol} / \mathrm{l})$} & \multirow[b]{2}{*}{$95 \% \mathrm{Cl}$} & \multirow[b]{2}{*}{ Cases } & \multirow[b]{2}{*}{ Number of person-years } & \multicolumn{2}{|c|}{ Model $1^{*}$} & \multirow[b]{2}{*}{$P_{\text {trend }}$} & \multicolumn{2}{|c|}{ Model $2 \dagger$} & \multirow[b]{2}{*}{$P_{\text {trend }}$} \\
\hline & & & & & $\mathrm{HR}$ & $95 \% \mathrm{Cl}$ & & $\mathrm{HR}$ & $95 \% \mathrm{Cl}$ & \\
\hline \multicolumn{11}{|l|}{ Lutein } \\
\hline Lowest (T1) & 0.37 & $0.36,0.38$ & 20 & 1953 & 1.00 & & & 1.00 & & \\
\hline Middle (T2) & 0.57 & $0.56,0.57$ & 25 & 2196 & $1 \cdot 12$ & $0.62,2.01$ & & $1 \cdot 14$ & $0.62,2.06$ & \\
\hline Highest (T3) & 0.85 & $0.83,0.87$ & 22 & 2024 & 1.03 & $0.56,1.92$ & 0.927 & 1.02 & $0.55,1.91$ & 0.958 \\
\hline \multicolumn{11}{|l|}{ Lycopene } \\
\hline Lowest (T1) & 0.13 & $0.12,0.14$ & 27 & 2037 & 1.00 & & & 1.00 & & \\
\hline Middle (T2) & 0.30 & $0.30,0.31$ & 20 & 2005 & 0.77 & $0.43,1.38$ & & 0.70 & $0.38,1.26$ & \\
\hline Highest (T3) & 0.55 & $0.53,0.57$ & 20 & 2131 & 0.72 & $0.40,1.32$ & 0.283 & 0.69 & $0.38,1.26$ & 0.224 \\
\hline \multicolumn{11}{|l|}{$a$-Carotene } \\
\hline Lowest (T1) & 0.08 & $0.08,0.09$ & 26 & 2077 & 1.00 & & & 1.00 & & \\
\hline Middle (T2) & 0.13 & $0.13,0.13$ & 22 & 2062 & 0.79 & $0.44,1.39$ & & 0.77 & $0.44,1.37$ & \\
\hline Highest (T3) & 0.23 & $0.22,0.24$ & 19 & 2034 & 0.75 & $0.41,1.36$ & 0.323 & 0.69 & $0.37,1.28$ & 0.231 \\
\hline \multicolumn{11}{|l|}{$\beta$-Carotene } \\
\hline Lowest (T1) & 0.35 & $0.34,0.37$ & 24 & 2029 & 1.00 & & & 1.00 & & \\
\hline Middle (T2) & 0.63 & $0.61,0.65$ & 30 & 2086 & 1.20 & $0.70,2.07$ & & $1 \cdot 12$ & $0.64,1.96$ & \\
\hline Highest (T3) & $1 \cdot 16$ & $1 \cdot 11,1 \cdot 21$ & 13 & 2058 & 0.52 & $0.26,1.05$ & 0.092 & 0.47 & $0.23,0.95$ & 0.041 \\
\hline \multicolumn{11}{|l|}{$\beta$-Cryptoxanthin } \\
\hline Lowest (T1) & 0.50 & $0.47,0.53$ & 20 & 1951 & 1.00 & & & 1.00 & & \\
\hline Middle (T2) & 1.42 & $1.38,1.47$ & 28 & 2081 & 1.26 & $0.70,2 \cdot 28$ & & 1.23 & $0.67,2.25$ & \\
\hline Highest (T3) & 3.39 & $3.25,3.54$ & 19 & 2141 & 0.82 & $0.42,1.60$ & 0.538 & 0.77 & $0.38,1.53$ & 0.404 \\
\hline \multicolumn{11}{|l|}{ Zeaxanthin } \\
\hline Lowest (T1) & $0 \cdot 17$ & $0.16,0.17$ & 18 & 2020 & 1.00 & & & 1.00 & & \\
\hline Middle (T2) & 0.23 & $0.23,0.23$ & 25 & 1832 & 1.52 & $0.82,2.79$ & & 1.47 & $0.80,2.72$ & \\
\hline Highest (T3) & 0.32 & $0.31,0.32$ & 24 & 2321 & $1 \cdot 13$ & $0.61,2.11$ & 0.764 & $1 \cdot 13$ & $0.61,2.11$ & 0.769 \\
\hline
\end{tabular}

* Model 1: age and sex were adjusted.

† Model 2: current tobacco use, regular alcohol intake, exercise habits and total energy were further adjusted. 
Table 3. Hazard ratios (HR) of tertiles of baseline serum carotenoid concentration on incidence of low HDL-cholesterol $(<1.04 \mathrm{mmol} / \mathrm{l})$ or high serum TAG ( $\geq 1.70 \mathrm{mmol} / \mathrm{l})$ (Mean values, HR and $95 \%$ confidence intervals)

\begin{tabular}{|c|c|c|c|c|c|c|c|c|c|c|}
\hline \multirow[b]{2}{*}{ Serum carotenoids } & \multirow[b]{2}{*}{ Mean $(\mu \mathrm{mol} / \mathrm{l})$} & \multirow[b]{2}{*}{$95 \% \mathrm{Cl}$} & \multirow[b]{2}{*}{ Cases } & \multirow[b]{2}{*}{ Number of person-years } & \multicolumn{2}{|c|}{ Model $1^{*}$} & \multirow[b]{2}{*}{$P_{\text {trend }}$} & \multicolumn{2}{|c|}{ Model $2 \dagger$} & \multirow[b]{2}{*}{$P_{\text {trend }}$} \\
\hline & & & & & $\mathrm{HR}$ & $95 \% \mathrm{Cl}$ & & $\mathrm{HR}$ & $95 \% \mathrm{Cl}$ & \\
\hline \multicolumn{11}{|l|}{ Lutein } \\
\hline Lowest (T1) & 0.37 & $0.36,0.38$ & 58 & 1503 & 1.00 & & & 1.00 & & \\
\hline Middle (T2) & 0.56 & $0.56,0.57$ & 67 & 1586 & 1.06 & $0.74,1.51$ & & 1.06 & $0.74,1.51$ & \\
\hline Highest (T3) & 0.83 & $0.80,0.85$ & 62 & 1540 & 0.97 & $0.67,1.40$ & 0.852 & 0.96 & $0.66,1.40$ & 0.838 \\
\hline \multicolumn{11}{|l|}{ Lycopene } \\
\hline Lowest (T1) & 0.13 & $0.12,0.14$ & 68 & 1531 & 1.00 & & & 1.00 & & \\
\hline Middle (T2) & 0.31 & $0.30,0.31$ & 64 & 1574 & 0.94 & $0.66,1.34$ & & 0.92 & $0.65,1.31$ & \\
\hline Highest (T3) & 0.56 & $0.54,0.58$ & 55 & 1524 & 0.87 & $0.60,1.25$ & 0.457 & 0.85 & $0.59,1.22$ & 0.372 \\
\hline \multicolumn{11}{|l|}{$a$-Carotene } \\
\hline Lowest (T1) & 0.09 & $0.08,0.09$ & 68 & 1491 & 1.00 & & & 1.00 & & \\
\hline Middle (T2) & 0.13 & $0.13,0.13$ & 64 & 1557 & 0.83 & $0.58,1.17$ & & 0.83 & $0.59,1.17$ & \\
\hline Highest (T3) & 0.23 & $0.22,0.24$ & 55 & 1581 & 0.70 & $0.49,1.01$ & 0.053 & 0.66 & $0.46,0.96$ & 0.028 \\
\hline \multicolumn{11}{|l|}{$\beta$-Carotene } \\
\hline Lowest (T1) & 0.36 & $0.34,0.38$ & 72 & 1427 & 1.00 & & & 1.00 & & \\
\hline Middle (T2) & 0.65 & $0.62,0.67$ & 62 & 1618 & 0.70 & $0.49,0.98$ & & 0.66 & $0.46,0.94$ & \\
\hline Highest (T3) & $1 \cdot 17$ & $1 \cdot 12,1 \cdot 22$ & 53 & 1584 & 0.57 & $0.39,0.83$ & 0.003 & 0.54 & $0.37,0.79$ & 0.002 \\
\hline \multicolumn{11}{|l|}{$\beta$-Cryptoxanthin } \\
\hline Lowest (T1) & 0.51 & $0.48,0.54$ & 63 & 1417 & 1.00 & & & 1.00 & & \\
\hline Middle (T2) & 1.44 & $1.39,1.49$ & 63 & 1571 & 0.79 & $0.55,1.13$ & & 0.76 & $0.52,1 \cdot 10$ & \\
\hline Highest (T3) & 3.32 & $3.17,3.47$ & 61 & 1641 & 0.68 & $0.46,1.01$ & 0.058 & 0.66 & $0.44,0.99$ & 0.048 \\
\hline \multicolumn{11}{|l|}{ Zeaxanthin } \\
\hline Lowest (T1) & 0.17 & $0.16,0.17$ & 63 & 1509 & 1.00 & & & 1.00 & & \\
\hline Middle (T2) & 0.23 & $0.23,0.23$ & 60 & 1447 & 0.99 & $0.69,1.41$ & & 1.00 & $0.70,1.43$ & \\
\hline Highest (T3) & 0.31 & $0.30,0.32$ & 64 & 1673 & 0.90 & $0.63,1.29$ & 0.569 & 0.92 & $0.64,1.32$ & 0.642 \\
\hline
\end{tabular}

${ }^{*}$ Model 1: age and sex were adjusted.

† Model 2: current tobacco use, regular alcohol intake, exercise habits and total energy were further adjusted. 
found that $\beta$-cryptoxanthin intakes were significantly associated with a reduced risk of type- 2 diabetes. Although there are some differences in the study design and study populations, we conclude that eating a diet rich in carotenoids, especially $\alpha$ - and $\beta$-carotene and $\beta$-cryptoxanthin, might help prevent the MetS and its components, especially abnormal lipid and/or glucose metabolism in middle-aged and older Japanese subjects.

On the other hand, it has been reported that cigarette smoking reduces serum carotenoid concentrations ${ }^{(52-54)}$. Interestingly, Hozawa et al. ${ }^{(55)}$ have found that higher serum carotenoid concentrations were associated with lower risk of diabetes and insulin resistance in non-smokers but not in smokers. From these results, oxidative stress induced by cigarette smoking may interact with the associations of serum carotenoids and the risks for developing the MetS and its components. Therefore, we also examined these associations stratified by smoking status. A significance inverse association of basal serum $\beta$-carotene and the risk for developing the MetS was also observed among non-smokers with the same level of significance as that of total subjects including both non-smokers and current smokers (data not shown). Interestingly, we found that, for $\beta$-cryptoxanthin, a borderline reduced risk was observed among non-smokers, with an HR (T3) of 0.50 (95\% CI 0.24, 1.04) and $P_{\text {linear trend }}$ of 0.07. On the other hand, in the current smokers, as coefficients did not converge, no further models could be fitted, because sample size of current smokers was too small for further data analyses. In contrast, we could not find any major differences in the associations between serum $\alpha$ - and $\beta$-carotene and $\beta$-cryptoxanthin concentrations and the risk for developing dyslipidaemia between subjects who were non-smokers and the total subjects (data not shown). From our results and previous findings, we concluded that carotenoids might help prevent the development of the MetS in non-smokers rather than in current smokers.

Our cohort study was conducted in the town of Mikkabi, Shizuoka Prefecture, Japan. Mikkabi is located in western Shizuoka, and approximately $40 \%$ of its residents work in agriculture. Fruit trees are the key industry in Mikkabi, which is an important producer of Japanese mandarin oranges in Japan. The subjects in this survey were residents of an area in which the Japanese mandarin orange is considerably more popular than in the rest of Japan. $\beta$-Cryptoxanthin is a carotenoid pigment that is particularly abundant in the Japanese mandarin orange ${ }^{(56,57)}$. Previously, we found that serum $\beta$-cryptoxanthin level increases sharply according to increased intake of Japanese mandarin oranges ${ }^{(58)}$. The average amount of fruit intake in the group with the highest serum $\beta$-cryptoxanthin was about $246 \mathrm{~g} / \mathrm{d}$, and it was approximately equal to three or four pieces of Japanese mandarin orange. Therefore, the serum concentrations of $\beta$-cryptoxanthin in our study population were widely distributed.

This study had some limitations. First, we could not evaluate the association of blood levels of other antioxidants such as vitamins $\mathrm{C}$ and $\mathrm{E}$ with the MetS. It would be necessary to measure the blood levels of vitamins $\mathrm{C}$ and $\mathrm{E}$ in order to examine the association of these antioxidant vitamin concentrations with the MetS and its complications. Second, we evaluated the MetS using BMI rather than waist circumference as a measure of obesity. Therefore, an analysis of the association of serum carotenoids with metabolic abnormalities of central obesity will be required. Last, in our study, the sample size was not particularly large, and thus it had less statistical power. Further studies on a larger scale will be required.

In conclusion, this longitudinal cohort study among middleaged and older Japanese subjects showed that the risk of developing the MetS was inversely associated with the baseline serum $\beta$-carotene concentration. Furthermore, the risk of developing abnormal lipid metabolism was inversely associated with serum $\alpha$ - and $\beta$-carotene and $\beta$-cryptoxanthin concentrations. Our findings further support the hypothesis that eating a diet rich in antioxidant carotenoids, especially $\alpha$-and $\beta$-carotene and $\beta$-cryptoxanthin, might help prevent the development of these chronic diseases. However, further evidence from epidemiological research is needed before a definitive conclusion on this issue can be drawn.

\section{Acknowledgements}

The authors are grateful to the participants in the survey and to the staff of the health examination programme for residents of the town of Mikkabi, Shizuoka, Japan. The authors are also grateful to the staff of the Seirei Preventive Health Care Center (Shizuoka, Japan).

This work was supported by a grant from the Ministry of Agriculture, Forestry, and Fisheries (MAFF) for a food research project titled 'Research project on the development of agricultural products and foods with health-promoting benefits (NARO)' and a grant from the Council for the Advancement of Fruit Tree Science.

M. S. was responsible for the study design, data collection and data management and carried out the data analysis and wrote the manuscript. M. N. was responsible for study design, data collection and data management and assisted in manuscript preparation. K. O., Y. I. and M. Y. were involved in the data collection and assisted in manuscript preparation.

The authors have declared that they have no conflicts of interest.

\section{Supplementary material}

For supplementary material/s referred to in this article, please visit http://dx.doi.org/doi:10.1017/S0007114515003268

\section{References}

1. National Cholesterol Education Program (NCEP) Expert Panel on Detection, Evaluation, and Treatment of High Blood Cholesterol in Adults (Adult Treatment Panel III) (2002) Third Report of the National Cholesterol Education Program (NCEP) Expert Panel on Detection, Evaluation, and Treatment of High Blood Cholesterol in Adults (Adult Treatment Panel III) final report. Circulation 106, 3143-3421.

2. Grundy SM (2005) Metabolic syndrome scientific statement by the American Heart Association and the National Heart, Lung, and Blood Institute. Arterioscler Thromb Vasc Biol 25, 2243-2244.

3. Ministry of Health, Labor and Welfare (Japanese government) (2015) National health and nutrition survey in 2012. http:// www.mhlw.go.jp/bunya/kenkou/eiyou/dl/h24-houkoku.pdf (accessed April 2015). 
4. Esmaillzadeh A, Kimiagar M, Mehrabi Y, et al. (2007) Dietary patterns, insulin resistance, and prevalence of the metabolic syndrome in women. Am J Clin Nutr 85, 910-918.

5. Yoo S, Nicklas T, Baranowski T, et al. (2004) Comparison of dietary intakes associated with metabolic syndrome risk factors in young adults: the Bogalusa Heart Study. Am J Clin Nutr 80, 841-848.

6. Steffen LM, Van Horn L, Daviglus ML, et al. (2014) A modified Mediterranean diet score is associated with a lower risk of incident metabolic syndrome over 25 years among young adults: the CARDIA (Coronary Artery Risk Development in Young Adults) study. Br J Nutr 112, 1654-1661.

7. Shin HJ, Cho E, Lee HJ, et al. (2014) Instant noodle intake and dietary patterns are associated with distinct cardiometabolic risk factors in Korea. J Nutr 144, 1247-1255.

8. Brader L, Uusitupa M, Dragsted LO, et al. (2014) Effects of an isocaloric healthy Nordic diet on ambulatory blood pressure in metabolic syndrome: a randomized SYSDIET sub-study. Eur J Clin Nutr 68, 57-63.

9. Nanri H, Nakamura K, Hara M, et al. (2011) Association between dietary pattern and serum C-reactive protein in Japanese men and women. J Epidemiol 21, 122-131.

10. Deshmukh-Taskar PR, O'Neil CE, Nicklas TA, et al. (2009) Dietary patterns associated with metabolic syndrome, sociodemographic and lifestyle factors in young adults: the Bogalusa Heart Study. Public Health Nutr 12, 2493-2503.

11. Baxter AJ, Coyne T \& McClintock C (2006) Dietary patterns and metabolic syndrome - a review of epidemiologic evidence. Asia Pac J Clin Nutr 15, 134-142.

12. Gutteridge JM (1994) Biological origin of free radicals, and mechanisms of antioxidant protection. Chem Biol Interact $\mathbf{9 1}$, 133-140.

13. Rock CL, Jacob RA \& Bowen PE (1996) Update on the biological characteristics of the antioxidant micronutrients: vitamin C, vitamin E, and the carotenoids. J Am Diet Assoc 96 , 693-702.

14. Lee KU (2001) Oxidative stress markers in Korean subjects with insulin resistance syndrome. Diabetes Res Clin Pract 54, S29-S33.

15. Hansel B, Giral P, Nobecourt E, et al. (2004) Metabolic syndrome is associated with elevated oxidative stress and dysfunctional dense high-density lipoprotein particles displaying impaired antioxidative activity. J Clin Endocrinol Metab 89, 4963-4971.

16. Ford ES, Mokdad AH, Giles WH, et al. (2003) The metabolic syndrome and antioxidant concentrations: findings from the Third National Health and Nutrition Examination Survey. Diabetes 52, 2346-2352.

17. Sugiura M, Nakamura M, Ogawa K, et al. (2008) Associations of serum carotenoid concentrations with the metabolic syndrome: interaction with smoking. $\mathrm{Br} J \mathrm{Nutr} \mathbf{1 0 0}$, 1297-1306.

18. Coyne T, Ibiebele TI, Baade PD, et al. (2009) Metabolic syndrome and serum carotenoids: findings of a cross-sectional study in Queensland, Australia. Br J Nutr 102, 1668-1677.

19. Sluijs I, Beulens JW, Grobbee DE, et al. (2009) Dietary carotenoid intake is associated with lower prevalence of metabolic syndrome in middle-aged and elderly men. $J$ Nutr 139, 987-992.

20. Suzuki K, Ito Y, Inoue T, et al. (2011) Inverse association of serum carotenoids with prevalence of metabolic syndrome among Japanese. Clin Nutr 30, 369-375.

21. Beydoun MA, Shroff MR, Chen X, et al. (2011) Serum antioxidant status is associated with metabolic syndrome among U.S. adults in recent national surveys. $J$ Nutr $\mathbf{1 4 1}$, 903-913.
22. Liu J, Shi WQ, Cao Y, et al. (2014) Higher serum carotenoid concentrations associated with a lower prevalence of the metabolic syndrome in middle-aged and elderly Chinese adults. Br J Nutr 112, 2041-2048.

23. Czernichow S, Vergnaud AC, Galan P, et al. (2009) Effects of long-term antioxidant supplementation and association of serum antioxidant concentrations with risk of metabolic syndrome in adults. Am J Clin Nutr 90, 329-335.

24. Sugiura M, Nakamura M, Ikoma Y, et al. (2005) High serum carotenoids are inversely associated with serum gammaglutamyltransferase in alcohol drinkers within normal liver function. J Epidemiol 15, 180-186.

25. Metabolic Syndrome Diagnostic Criteria Examination Committee (2005) Definition and the diagnostic standard for metabolic syndrome - Committee to Evaluate Diagnostic Standards for Metabolic Syndrome. Nippon Naika Gakkai Zasshi 94, 794-809 (in Japanese).

26. Matsuzawa Y (2005) Metabolic syndrome - definition and diagnostic criteria in Japan. J Atheroscler Thromb 12, 301.

27. Matsuzawa Y, Inoue S, Ikeda Y, et al. (2000) New definition of obesity and diagnostic criteria for high-risk obesity. Himan Kenkyu 6, 12-28 (in Japanese).

28. Jay D, Hitomi H \& Griendling KK (2006) Oxidative stress and diabetic cardiovascular complications. Free Radic Biol Med 40, 183-192.

29. Griendling KK \& FitzGerald GA (2003) Oxidative stress and cardiovascular injury: part II: animal and human studies. Circulation 108, 2034-2040.

30. Oberly LW (1988) Free radicals and diabetes. Free Radic Biol Med 5, 113-124.

31. Dandona P, Thusu K, Cook S, et al. (1996) Oxidative damage to DNA in diabetes mellitus. Lancet 347, 444-445.

32. Evans JL, Goldfine ID, Maddux BA, et al. (2002) Oxidative stress and stress-activated signaling pathways: a unifying hypothesis of type 2 diabetes. Endocr Rev 23, 599-622.

33. Marseglia L, Manti S, D'Angelo G, et al. (2014) Oxidative stress in obesity: a critical component in human diseases. Int J Mol Sci 16, 378-400.

34. Maddux BA, See W, Lawrence JC Jr, et al. (2001) Protection against oxidative stress-induced insulin resistance in rat L6 muscle cells by mircomolar concentrations of alphalipoic acid. Diabetes 50, 404-410.

35. Rudich A, Tirosh A, Potashnik R, et al. (1998) Prolonged oxidative stress impairs insulin-induced GLUT4 translocation in 3T3-L1 adipocytes. Diabetes 47, 1562-1569.

36. Matsuoka T, Kajimoto Y, Watada H, et al. (1997) Glycationdependent, reactive oxygen species-mediated suppression of the insulin gene promoter activity in HIT cells. J Clin Invest 99, $144-150$

37. Nakazono K, Watanabe N, Matsuno K, et al. (1991) Does superoxide underlie the pathogenesis of hypertension? Proc Natl Acad Sci U S A 88, 10045-10048.

38. Ohara Y, Peterson TE \& Harrison DG (1993) Hypercholesterolemia increases endothelial superoxide anion production. J Clin Invest 91, 2546-2551.

39. Stanner SA, Hughes J, Kelly CN, et al. (2004) A review of the epidemiological evidence for the antioxidant hypothesis. Public Health Nutr 7, 407-422.

40. Knekt P, Ritz J, Pereira MA, et al. (2004) Antioxidant vitamins and coronary heart disease risk: a pooled analysis of 9 cohorts. Am J Clin Nutr 80, 1508-1520.

41. Ford ES, Will JC, Bowman BA, et al. (1999) Diabetes mellitus and serum carotenoids: findings from the Third National Health and Nutrition Examination Survey. Am J Epidemiol 149, 168-176.

42. Hozawa A, Jacobs DR Jr, Steffes MW, et al. (2009) Circulating carotenoid concentrations and incident hypertension: the 
Coronary Artery Risk Development in Young Adults (CARDIA) study. J Hypertens 27, 237-242.

43. Gey KF, Stahelin HB \& Eichholzer M (1993) Poor plasma status of carotene and vitamin $\mathrm{C}$ is associated with higher mortality from ischemic heart disease and stroke: Basel Prospective Study. Clin Investig 71, 3-6.

44. Ito Y, Kurata M, Suzuki K, et al. (2006) Cardiovascular disease mortality and serum carotenoid levels: a Japanese populationbased follow-up study. J Epidemiol 16, 154-160.

45. Morris DL, Kritchevsky SB \& Davis CE (1994) Serum carotenoids and coronary heart disease. The Lipid Research Clinics Coronary Primary Prevention Trial and Followup Study. JAMA 272, 1439-1441.

46. Arnlöv J, Zethelius B, Risérus U, et al. (2009) Serum and dietary beta-carotene and alpha-tocopherol and incidence of type 2 diabetes mellitus in a community-based study of Swedish men: report from the Uppsala Longitudinal Study of Adult Men (ULSAM) study. Diabetologia 52, 97-105.

47. Czernichow S, Bertrais S, Blacher J, et al. (2005) Effect of supplementation with antioxidants upon long-term risk of hypertension in the SU.VI.MAX study: association with plasma antioxidant levels. J Hypertens 23, 2013-2018.

48. Czernichow S, Couthouis A, Bertrais S, et al. (2006) Antioxidant supplementation does not affect fasting plasma glucose in the Supplementation with Antioxidant Vitamins and Minerals (SU.VI.MAX) study in France: association with dietary intake and plasma concentrations. Am J Clin Nutr 84, 395-399.

49. Bonet ML, Ribot J \& Palou A (2012) Lipid metabolism in mammalian tissues and its control by retinoic acid. Biochim Biophys Acta 1821, 177-189.

50. Sugiura M, Nakamura M, Ikoma Y, et al. (2006) The homeostasis model assessment-insulin resistance index is inversely associated with serum carotenoids in non-diabetic subjects. $J$ Epidemiol 16, 71-78.

51. Montonen J, Knekt P, Järvinen R, et al. (2004) Dietary antioxidant intake and risk of type 2 diabetes. Diabetes Care 27, 362-366.

52. Gabriel HE, Liu Z, Crott JW, et al. (2006) A comparison of carotenoids, retinoids, and tocopherols in the serum and buccal mucosa of chronic cigarette smokers versus nonsmokers. Cancer Epidemiol Biomarkers Prev 15, 993-999.

53. Widome R, Jacobs DR Jr, Hozawa A, et al. (2010) Passive smoke exposure and circulating carotenoids in the CARDIA study. Ann Nutr Metab 56, 113-118.

54. Sugiura M, Nakamura M, Ogawa K, et al. (2009) Synergistic interaction of cigarette smoking and alcohol drinking with serum carotenoid concentrations: findings from a middle-aged Japanese population. Br J Nutr 102, 1211-1219.

55. Hozawa A, Jacobs DR Jr, Steffes MW, et al. (2006) Associations of serum carotenoid concentrations with the development of diabetes and with insulin concentration: interaction with smoking: the Coronary Artery Risk Development in Young Adults (CARDIA) Study. Am J Epidemiol 163, 929-937.

56. Goodner KL, Rouseff RL \& Hofsommer HJ (2001) Orange, mandarin, and hybrid classification using multivariate statistics based on carotenoid profiles. J Agric Food Chem 49 , 1146-1150.

57. Holden JM, Eldridge AL, Beecher GR, et al. (1999) Carotenoid content of U.S. foods: an update of the database. J Food Comp Anal 12, 169-196.

58. Sugiura M, Matsumoto H, Kato M, et al. (2004) Multiple linear regression analysis of the seasonal changes in the serum concentration of beta-cryptoxanthin. J Nutr Sci Vitaminol (Tokyo) 50, 196-202. 